\title{
Optimal management of carpal tunnel syndrome
}

This article was published in the following Dove Press journal:

International Journal of General Medicine

25 August 2010

Number of times this article has been viewed

\section{Shimpei Ono \\ Philip J Clapham \\ Kevin C Chung \\ Section of Plastic Surgery, Department of Surgery, University of Michigan Health System, Ann Arbor, MI, USA}

Abstract: In order to improve health care efficiency and effectiveness, treatments should provide disease improvement or resolution at a reasonable cost. The American Academy of Orthopedic Surgeons (AAOS) published a guideline for treatment of carpal tunnel syndrome (CTS) in 2009 based on review of the literature up to April 6, 2007. We have now reviewed the material published since then. Through reviewing evidence-based articles published during this period, this paper examines the current options and trends for treating CTS. We performed a systematic review of the randomized controlled trials, meta-analyses, systematic reviews, and practice guidelines to present the outcomes of current treatments for this disease. Twenty-five studies met our inclusion criteria. Thirteen randomized, controlled trials and 12 systematic reviews, including three Cochrane database systematic reviews, were retrieved. Our review revealed that most of the recent studies support the AAOS guideline. However, the recent literature demonstrates a trend towards recommending early surgery for CTS cases with or without median nerve denervation, although the AAOS guideline recommends early surgical treatment only for cases with denervation. The usefulness of splinting and steroids as initial treatments for improving patients' symptoms are also supported by the recent literature, but these effects are temporary. The evidence level for ultrasound treatment is still low, and further studies are needed to determine the effectiveness of this treatment. Finally, our review revealed a paucity of articles comparing the costs of CTS diagnosis and treatment. With the recent focus on health care reform and rising costs, attention to the direct and indirect costs of health care is important for all conditions. Future well designed studies should include cost analyses to help determine the cost burden of CTS.

Keywords: carpal tunnel syndrome, treatment, outcomes, evidence-based medicine

\section{Introduction}

Carpal tunnel syndrome (CTS), or median neuropathy, is a pathologic condition in which the median nerve is compressed at the wrist, leading to pain, paresthesia, numbness, and weakness in the median nerve distribution of the hand (Figure 1). CTS is a common peripheral nerve entrapment syndrome that has received a lot of attention because of its association with work-related disability. ${ }^{1-3}$

\section{Epidemiology}

CTS is one of the most common hand disorders and entrapment neuropathies. The highest incidence is among middle-aged and elderly women. ${ }^{4,5}$ The CTS incidence rate in the US has been estimated at 1-3 per 1000 persons per year. ${ }^{6}$ The prevalence is approximately 50 cases per 1000 subjects in the general population. ${ }^{6,7}$ 


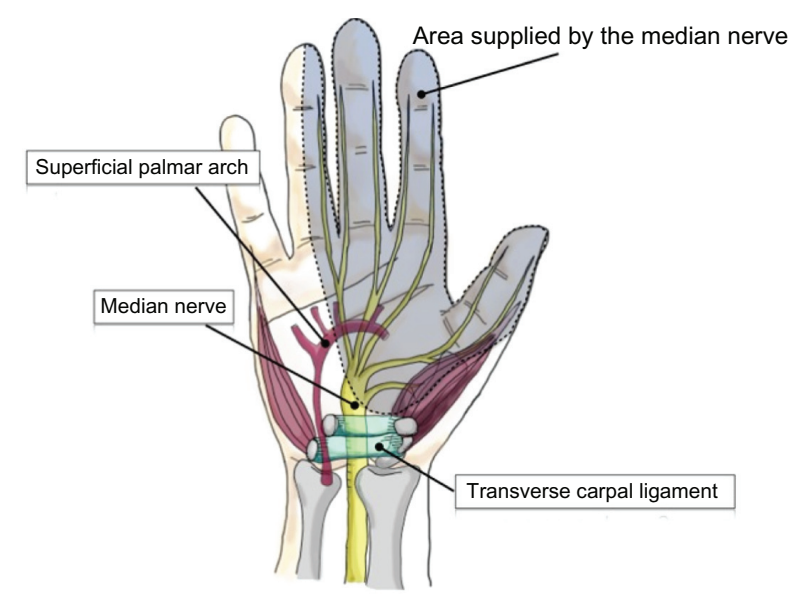

Figure I The carpal tunnel is a passageway through which nine flexor tendons and the median nerve pass in order to supply function, feeling, and movement to the thumb, index, middle and half of the ring finger.

The large prevalence of CTS is an important issue in the workplace because it is directly related to waning productivity resulting from work disability ${ }^{1-3}$ and is associated with high-cost treatment. ${ }^{8}$ According to a 2008 report from the Bureau of Labor Statistics, CTS is associated with the second longest average time away from work (28 days) out of the major disabling diseases and illnesses in all private industries. ${ }^{9}$ Also, according to the National Institutes of Health, the average lifetime cost of CTS, including medical bills and loss time from work, is approximately $\$ 30,000$ for each affected worker. ${ }^{10} \mathrm{As}$ a result, choosing the proper treatment for CTS is crucial in improving patient quality of life and containing medical costs to a reasonable level.

\section{Objectives}

The aim of this article is to provide an evidence-based review of the most current treatment options and trends for CTS, including both conservative and surgical treatments.

In 2008, a systematic review and practice guideline entitled "Clinical Practice Guideline on the Treatment of Carpal Tunnel Syndrome" was undertaken by the American Academy of Orthopaedic Surgeons (AAOS), the summary of which was published in 2009. ${ }^{11}$ This guideline consists of nine specific recommendations and is useful for evidence-based clinical practice. The literature search undertaken in creating this guideline included articles from 1966 through April 6, 2007. Almost three years have passed since this search and many new articles with high evidence-based analysis have been published. For clinicians to adhere to the most current evidence-based recommendations, it is important that we update the literature on treatment options and outcomes on a routine basis. In order to improve health care efficiency and effectiveness, treatments should provide disease improvement or resolution at a reasonable cost. For common conditions like CTS, preferentially allocating resources to a more effective treatment may have a large impact on reducing the overall national costs of treatment. Furthermore, the practice of patient-centered care by considering patients' needs and activity levels are essential considerations in disease management.

\section{Material and methods Literature identification}

The aim of our review is to provide optimal treatment recommendations based on the evidence available in the literature. We conducted a literature search using MedLine and the Cochrane Library to identify all citations of original research studies related to treatment in CTS. Details of the search strategy are given in Table 1.

\section{Selection of studies}

Based on title and abstract, two reviewers independently selected the trials to be included in this review. All articles selected by at least one of the reviewers were retrieved for examination. Articles fulfilling all the following inclusion criteria were included in the final review: (1) type of article (meta-analysis, practice guideline, randomized controlled trial or systematic review), (2) publication in English language, (3) published between April 7, 2007 and May 28, 2010, (4) study sample consisting of patients with clinically and/ or electrophysiologically confirmed CTS, and (5) evaluation of the efficacy of one or more treatment options. Reference lists of all relevant studies from the electronic search were manually searched to identify additional eligible studies.

\section{Quality assessment}

We considered the quality of the available evidence. Quality was determined using a "levels of evidence" approach, comprising five levels (Table 2). The higher the level of evidence, the greater the ability to draw causal inferences from the results of a study and, hence, the greater the quality of that study. This quality assessment is the same as that used

Table I Search strategy

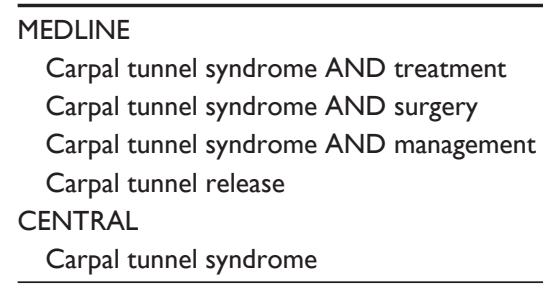


Table 2 Levels of evidence for therapeutic studies investigating the results of treatment

Level I
High quality, randomized trial with statistically significant difference or
no statistically significant difference but narrow confidence intervals
Systematic review of Level I randomized controlled trials (and study
results were homogenous)
Level II
Lesser quality randomized controlled trial ( $<80 \%$ follow-up, no
blinding, or improper randomization)
Prospective comparative study
Systematic review of Level II or Level I studies with inconsistent
results
Level III
Case-control study
Retrospective comparative study
Systematic review of Level III studies
Level IV
Case series
Level V
Expert opinion

for formulation of the AAOS Guideline on the Treatment of Carpal Tunnel Syndrome, available from http://www.aaos. org/Research/Committee/Evidence/loetable1.pdf.

\section{Data extraction and synthesis}

The selected studies were gathered on the basis of kind of intervention, ie, surgical procedure, nonsurgical procedure, and postoperative treatment. The following data were extracted independently by two reviewers: characteristics of study design, population (size, age, gender, and duration of disease), intervention (details about surgical procedure), length of follow-up, outcome evaluation, and overall clinical results. Conclusions of our search were compared with existing evidence or added as new knowledge. We discussed differences in recommendations based on outcomes and costeffectiveness based on the evidence in the CTS literature and the AAOS guidelines.

\section{Results and discussion}

Twenty-five studies met our inclusion criteria. Thirteen randomized controlled trials and 12 systematic reviews, including three Cochrane database systematic reviews, were retrieved.

\section{Surgical versus nonsurgical treatment}

Optimal treatment of CTS should be patient-oriented to provide patients with relief of symptoms, and as noninvasively, permanently, and inexpensively as possible. The treatment options for CTS are divided into two major groups, ie, nonsurgical and surgical. In 1993, the American Academy of Neurology's official practice guidelines recommended treating CTS with noninvasive options first and considering surgery only if noninvasive treatment proved ineffective. ${ }^{12}$ In recent years, however, initial surgical management has gained support, due to more accurate diagnostic techniques and the increased number of trained hand surgeons in the community. ${ }^{13}$ However, there is still controversy over whether surgical or nonsurgical treatment should be chosen as the initial treatment of CTS.

The AAOS guideline for the treatment of $\mathrm{CTS}^{14,15}$ recommends both nonsurgical and surgical treatments for early CTS without denervation of the median nerve, although they also recommend an initial course of nonoperative treatment. Surgery can then be considered if there is clinical evidence of median nerve denervation or if the patient would prefer surgery over conservative management. ${ }^{14}$ In fact, the recent literature demonstrates a trend towards recommending early surgery with or without median nerve denervation. ${ }^{13}$ In 2009, a study of 116 patients with CTS compared the treatment outcomes between an experimental group of 57 patients who received surgical management and a control group of 59 patients who received a nonsurgical treatment regimen of hand therapy and ultrasound. The results showed that the surgical group achieved modestly better outcomes in terms of hand function and symptoms at both three months and one year when compared with the control group (Level I). ${ }^{13}$ Another meta-analysis concluded that surgical treatment relieves symptoms better than splinting, but the evidence for surgical treatment being superior to steroid injections is unclear (Level I). ${ }^{16}$ Therefore, more research is needed to determine the best treatment for patients with mild to moderate symptoms, as well as to identify which patients should forego conservative management and undergo surgery as the initial treatment.

Moreover, several economic analyses suggest that surgery should be considered as the initial form of treatment when the diagnosis of CTS is confirmed by nerve conduction studies, because the surgical treatment option has the most favorable cost-utility ratio. ${ }^{17,18}$

\section{Nonsurgical treatments}

Only three conservative treatments are supported by a substantial body of experimental evidence: splinting, steroids, and ultrasound. ${ }^{19}$ The AAOS recommends that when initial conservative treatment fails to resolve a patient's symptoms within 2-7 weeks, physicians should move on to another nonoperative treatment or surgery. 


\section{Splinting}

For patients with mild CTS symptoms, the simplest treatment is a night splint. Splinting has the advantage of being inexpensive and is associated with a minimal complication rate. The immobilization may decrease the pressure around the soft tissue in the carpal tunnel, which enhances blood circulation and relieves pressure on the median nerve. For this reason, splinting provides many patients with relief from the numbness and tingling sensation experienced at night or during extended periods of rest. For some patients, wearing a splint may also be necessary during the day. The AAOS recommends that splinting be considered before surgery when treating CTS. Recent evidence-based studies (Level II) ${ }^{19,20}$ also support this suggestion. Specifically, research suggests that a splint that maintains the wrist in the neutral position may be more effective than a wrist cock-up splint (Level II). ${ }^{21}$ We can conclude that splinting for CTS is useful for relief of some symptoms in the early stages of CTS, and has the benefits of being cost-effective and without serious adverse effects. It should be considered as an initial treatment option before considering surgery, especially in mild or moderate cases.

\section{Steroids}

The AAOS recommends local steroid injection when treating CTS before surgery is considered, and oral steroids as a secondary option. Their report also concluded that steroids are more effective than nonsteroidal anti-inflammatory drugs and diuretics, but also have the potential for more serious side effects. This conclusion is supported by a recent study by Marshall et al who concluded that local steroid injections are more effective than oral steroids for up to three months (Level II). ${ }^{22}$ On the other hand, another recent study indicated that local steroid injection and nonsteroidal anti-inflammatory drugs with concomitant use of wrist splints might offer patients with CTS variable and effective treatment options for the management of functional scores and nerve conduction parameters (Level II). ${ }^{23}$ Moreover, a further study revealed that corticosteroid iontophoresis was not effective in the treatment of mild to moderate CTS (Level II).

As a result, steroid treatment for CTS, particularly local injection, is effective for temporary relief of symptoms in many patients. However, the efficacy and duration of symptom relief with the steroid injections are still unknown. Further investigation is needed to determine the long-term outcomes of local steroid injection and how many times and how frequently the steroid injections should be repeated.

\section{Ultrasound}

Ultrasound treatment consists of directing high-frequency sound waves at the inflamed area. The sound waves are converted into heat in the deep tissues of the hand, and are presumed to open the blood vessels, allowing oxygen to be delivered to the injured tissue. As a result, it is suggested that ultrasound therapy may accelerate the healing process in damaged tissues. ${ }^{24}$ It is often prescribed along with nerve and tendon exercises. The AAOS guideline recommends ultrasound treatment of CTS. However, this recommendation was based on the results of only two studies, hence the low evidence level of this recommendation..$^{24,25}$ To increase the evidence level of ultrasound treatment for CTS, we need further studies comparing an ultrasound group against a placebo group. There was no updated information in this regard.

\section{Surgical treatments}

Carpal tunnel release (CTR) is the most common hand and wrist surgery performed in the US, with an estimated 400,000 operations performed per year. ${ }^{26} \mathrm{CTR}$ as an effective treatment for CTS is supported by high quality evidence. ${ }^{14}$ There are several variations of CTR surgery. The two major types are open carpal tunnel release (OCTR) and endoscopic carpal tunnel release (ECTR). OCTR can be further classified into full-open and mini-open with a one inch incision. Regardless of selection of these treatment options, the most important thing is complete division of the flexor retinaculum. ${ }^{14}$

\section{Open carpal tunnel release}

Traditionally, OCTR was done through a relatively large 4-5 cm longitudinal incision extending from Kaplan's cardinal line distally to beyond the wrist crease proximally (Figure 2). Over time, the size of this incision has gradually decreased, and most hand surgeons today perform primary OCTR through a $2-4 \mathrm{~cm}$ incision, which ends approximately $2 \mathrm{~cm}$ distal to the wrist crease. OCTR has been shown to be an effective and relatively safe procedure, and is established as the standard surgical treatment for CTS. ${ }^{27,28}$ It has produced uniformly excellent results, with high patient satisfaction and a low complication rate..$^{29,30}$ The outcome of this procedure can be complicated by scar tenderness, grip and pinch weakness, and pillar pain, which are all related to the incision.

There are two recent publications concerning OCTR. The Cochrane database of systematic reviews concluded that there was no strong evidence supporting the need for replacement 


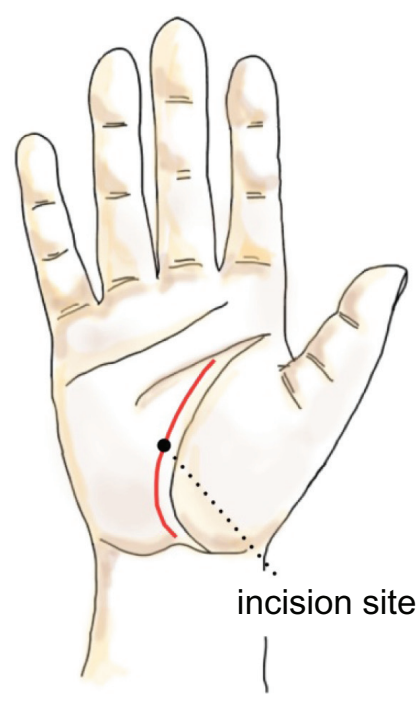

Figure 2 Open carpal tunnel release.

of standard OCTR by alternative surgical procedures for the treatment of CTR (Level I). ${ }^{31}$ In contrast, the other study compared conventional OCTR with the double-incision technique and showed that the limited open technique using the double incision was advantageous compared with the standard technique in tackling scar-related morbidities in terms of decreasing pillar pain and scar sensitivity (Level II). ${ }^{32}$

\section{Endoscopic carpal tunnel release}

ECTR refers to a method of performing CTR using an endoscope or arthroscopic device ${ }^{33}$ (Figure 3). This entails

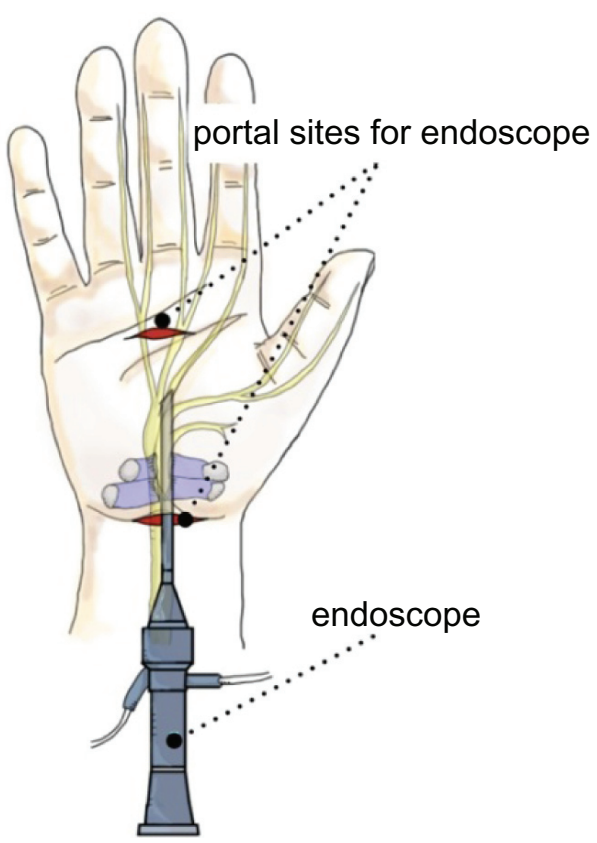

Figure 3 Endoscopic carpal tunnel release.

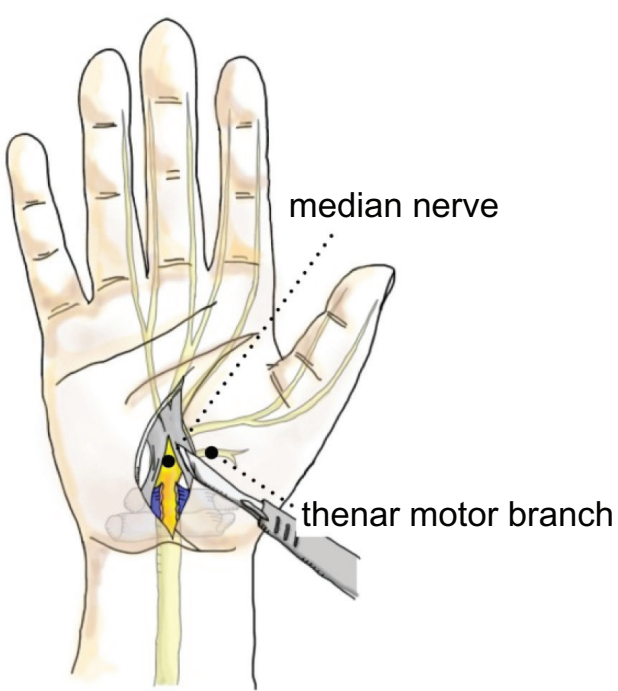

a less invasive procedure than standard OCTR. ECTR was invented to address the potential complications of OCTR by using smaller incisions placed away from the middle of the palm. ${ }^{34,35}$ It is assumed that preservation of the superficial fascia and adipose tissue over the flexor retinaculum allows faster recovery of grip strength, less scar tenderness and pillar pain, and earlier return to work. ${ }^{35,36}$ According to the AAOS guideline, ${ }^{14}$ endoscopic release offers better outcomes than OTCR at 12 weeks after surgery in terms of pain relief, time until return to work, and wound-related complications. In recent studies comparing OCTR and two-portal ECTR, Atroshi et $\mathrm{al}^{37}$ reported that the outcomes were equivalent, other than ECTR offering a shorter recovery period. However, critics of ECTR report higher complication rates ${ }^{38-40}$ due to the technical difficulty of the procedure, as well as greater cost when compared with OCTR. ${ }^{35,41}$ However, experienced surgeons can successfully complete the operation without too many complications. ${ }^{42}$ Therefore, the decision to perform ECTR is influenced by the surgeon's experience and patient factors, including occupation, socioeconomic status, and preference. This evidence is also supported by the recent Cochrane database systematic review. They concluded that the decision to perform ECTR instead of OCTR seems to be guided by the surgeon's and patient's preferences (Level I). ${ }^{31}$

\section{Mini-open carpal tunnel release $\mathrm{e}^{43,44}$}

In recent years, many surgeons have adopted the "mini" OCTR, also called the short-incision procedure. The idea behind the "mini" procedure is to combine the simplicity and safety of OCTR with the reduced tissue trauma and 

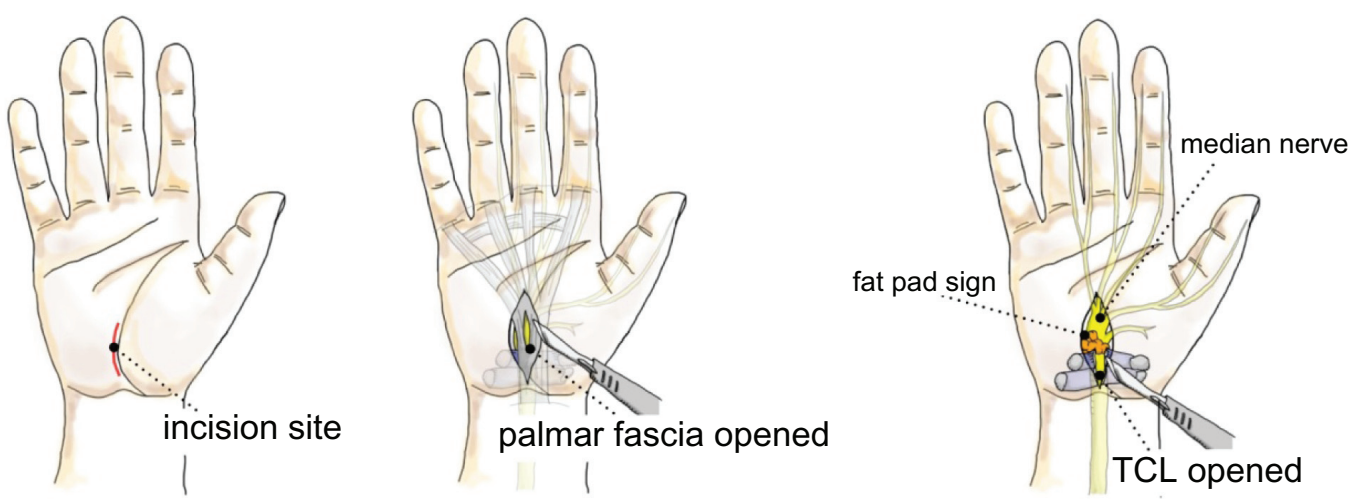

Figure 4 Mini-open carpal tunnel release.

Abbreviation: TCL, transverse carpal ligament.

postoperative morbidity of ECTR by using a short-incision, open technique. The incision begins just distal to the distal wrist crease and extends no further than Kaplan's cardinal line, which extends along the distal border of the outstretched thumb obliquely toward the pisiform (Figure 4).

According to the AAOS guideline, when minimal incision release was compared with open release in Level I studies, minimal incision release offered superior outcomes in terms of symptom relief, functional status, and scar tenderness. When compared with endoscopic release, minimal incision was favored when pain at two or four weeks was the outcome measure. ${ }^{14,42}$ On the other hand, Cellocco et $\mathrm{al}^{45}$ prospectively compared the safety and effectiveness of mini-incision (less than $2 \mathrm{~cm})$, and a limited open technique $(3-4 \mathrm{~cm}$ ) for CTR in 185 consecutive patients, with a five-year minimum follow-up. Patient status was evaluated with a modified version of the Boston Carpal Tunnel questionnaire, administered preoperatively and at 19, 30, and 60 months postoperatively. Mini-incision CTR had superior outcomes over the standard technique in terms of recovery time, pillar pain, and recurrence rate (Level II).

\section{Conclusion}

In order to improve health care efficiency and effectiveness, treatments should provide disease improvement or resolution at reasonable cost. Furthermore, we should always think about patient-centered care in determining the best treatment for each patient's condition. When considering the treatment options for CTS, only four treatments are supported by some evidence: splinting, steroids, ultrasound, and surgery. Splinting and steroids are useful as initial treatment for improving symptoms, but their effects are temporary. The evidence level for ultrasound treatment is poor and further investigations are needed. Moreover, early treatment using mini-OCTR appears to be the preferred treatment approach.

\section{Disclosure}

The authors report no conflict of interest in this work.

\section{References}

1. Katz JN, Lew RA, Bessette L, et al. Prevalence and predictors of longterm work disability due to carpal tunnel syndrome. Am J Ind Med. 1998;33(6):543-550.

2. Feuerstein M, Miller VL, Burrell LM, Berger R. Occupational upper extremity disorders in the federal workforce. Prevalence, health care expenditures, and patterns of work disability. J Occup Environ Med. 1998;40(6):546-555.

3. Latinovic R, Gulliford MC, Hughes RA. Incidence of common compressive neuropathies in primary care. J Neurol Neurosurg Psychiatry. 2006;77(2):263-265.

4. Becker J, Nora DB, Gomes I, et al. An evaluation of gender, obesity, age and diabetes mellitus as risk factors for carpal tunnel syndrome. Clin Neurophysiol. 2002;113(9):1429-1434.

5. Geoghegan JM, Clark DI, Bainbridge LC, Smith C, Hubbard R. Risk factors in carpal tunnel syndrome. J Hand Surg Br. 2004;29(4): 315-320.

6. Ashworth N. Carpal Tunnel Syndrome. Available from: http://www. emedicine.com/pmr/topic21.htm. Accessed on May 28, 2010.

7. Fuller D. Carpal Tunnel Syndrome. Available from: http://www. emedicine.com/orthoped/topic455.htm. Accessed on 28 May, 2010.

8. Hanrahan LP, Higgins D, Anderson H, Smith M. Wisconsin occupational carpal tunnel syndrome surveillance: The incidence of surgically treated cases. Wis Med J. 1993;92(12):685-689.

9. US Department of Labor Bureau of Labor Statistics. Available from: http:// www.bls.gov/news.release/osh2.t11.htm. Accessed on Jun 23, 2010.

10. National Institute of Neurological Diseases and Stroke (NINDS). Available from: http://www.ninds.nih.gov/disorders/carpal_tunnel/ detail_carpal_tunnel.htm. Accessed on Jun 24, 2010.

11. Keith MW, Masear V, Chung KC, et al. American Academy of Orthopaedic Surgeons Clinical Practice Guideline on diagnosis of carpal tunnel syndrome. J Bone Joint Surg Am. 2009;91(10):2478-2479.

12. Practice parameter for carpal tunnel syndrome (summary statement). Report of the Quality Standards Subcommittee of the American Academy of Neurology. Neurology. 1993;43(11):2406-2409.

13. Jarvik JG, Comstock BA, Kliot M, et al. Surgery versus non-surgical therapy for carpal tunnel syndrome: A randomised parallel-group trial. Lancet. 2009;374(9695):1074-1081.

14. Keith MW, Masear V, Amadio PC, et al. Treatment of carpal tunnel syndrome. J Am Acad Orthop Surg. 2009;17(6):397-405. 
15. American Academy of OrthopaedicSurgeons Work Group Panel. Clinical practice guideline on the treatment of carpal tunnel syndrome. Available at: www.aaos.org/research/guidelines/CTStreatmentguide. asp. Accessed on Jun 24, 2010.

16. Verdugo RJ, Salinas RA, Castillo JL, Cea JG. Surgical versus non-surgical treatment for carpal tunnel syndrome. Cochrane Database Syst Rev. 2008(4):CD001552.

17. Pomerance J, Zurakowski D, Fine I. The cost-effectiveness of nonsurgical versus surgical treatment for carpal tunnel syndrome. J Hand Surg Am. 2009;34(7):1193-1200.

18. Haase SC, Chung KC. The cost-effectiveness of nonsurgical versus surgical treatment for carpal tunnel syndrome: Invited commentary. J Hand Surg Am. 2009;34(7):1201-1203.

19. Piazzini DB, Aprile I, Ferrara PE, et al. A systematic review of conservative treatment of carpal tunnel syndrome. Clin Rehabil. 2007;21(4):299-314.

20. de Angelis MV, Pierfelice F, Di Giovanni P, Staniscia T, Uncini A. Efficacy of a soft hand brace and a wrist splint for carpal tunnel syndrome: A randomized controlled study. Acta Neurol Scand. 2009; 119(1):68-74.

21. Brininger TL, Rogers JC, Holm MB, Baker NA, Li ZM, Goitz RJ. Efficacy of a fabricated customized splint and tendon and nerve gliding exercises for the treatment of carpal tunnel syndrome: A randomized controlled trial. Arch Phys Med Rehabil. 2007;88(11):1429-1435.

22. Marshall S, Tardif G, Ashworth N. Local corticosteroid injection for carpal tunnel syndrome. Cochrane Database Syst Rev. 2007(2):CD001554.

23. Gurcay E, Unlu E, Gurcay AG, Tuncay R, Cakci A. Evaluation of the effect of local corticosteroid injection and anti-inflammatory medication in carpal tunnel syndrome. Scott Med J. 2009;54(1):4-6.

24. Bakhtiary AH, Rashidy-Pour A. Ultrasound and laser therapy in the treatment of carpal tunnel syndrome. Aust J Physiother. 2004;50(3): 147-151.

25. O’Connor D, Marshall S, Massy-Westropp N. Non-surgical treatment (other than steroid injection) for carpal tunnel syndrome. Cochrane Database Syst Rev. 2003(1):CD003219.

26. Concannon MJ, Brownfield ML, Puckett CL. The incidence of recurrence after endoscopic carpal tunnel release. Plast Reconstr Surg. 2000;105(5):1662-1665.

27. Phalen GS. Reflections on 21 years' experience with the carpal-tunnel syndrome. JAMA. 1970;212(8):1365-1367.

28. Pfeffer GB, Gelberman RH, Boyes JH, Rydevik B. The history of carpal tunnel syndrome. J Hand Surg Br. 1988;13(1):28-34.

29. Gerritsen AA, Uitdehaag BM, van Geldere D, Scholten RJ, de Vet HC, Bouter LM. Systematic review of randomized clinical trials of surgical treatment for carpal tunnel syndrome. Br J Surg. 2001;88(10): 1285-1295.
30. Kulick MI, Gordillo G, Javidi T, Kilgore ES Jr, Newmayer WL 3rd. Long-term analysis of patients having surgical treatment for carpal tunnel syndrome. J Hand Surg Am. 1986;11(1):59-66.

31. Scholten RJ, Mink van der Molen A, Uitdehaag BM, Bouter LM, de Vet HC. Surgical treatment options for carpal tunnel syndrome. Cochrane Database Syst Rev. 2007(4):CD003905.

32. Hamed AR, Makki D, Chari R, Packer G. Double- versus single-incision technique for open carpal tunnel release. Orthopedics. 2009;32(10).

33. Okutsu I, Ninomiya S, Takatori Y, Ugawa Y. Endoscopic management of carpal tunnel syndrome. Arthroscopy. 1989;5(1):11-18.

34. Mackenzie DJ, Hainer R, Wheatley MJ. Early recovery after endoscopic vs short-incision open carpal tunnel release. Ann Plast Surg. 2000; 44(6):601-604.

35. Ferdinand RD, MacLean JG. Endoscopic versus open carpal tunnel release in bilateral carpal tunnel syndrome. A prospective, randomised, blinded assessment. J Bone Joint Surg Br. 2002;84(3):375-379.

36. Trumble TE, Diao E, Abrams RA, Gilbert-Anderson MM. Singleportal endoscopic carpal tunnel release compared with open release: A prospective, randomized trial. J Bone Joint Surg Am. 2002;84A(7): 1107-1115.

37. Atroshi I, Hofer M, Larsson GU, Ornstein E, Johnsson R, Ranstam J. Open compared with 2-portal endoscopic carpal tunnel release: A 5-year follow-up of a randomized controlled trial. J Hand Surg Am. 2009;34(2):266-272.

38. Chow JC. Endoscopic release of the carpal ligament for carpal tunnel syndrome: 22-month clinical result. Arthroscopy. 1990;6(4):288-296.

39. Palmer DH, Paulson JC, Lane-Larsen CL, Peulen VK, Olson JD. Endoscopic carpal tunnel release: A comparison of two techniques with open release. Arthroscopy. 1993;9(5):498-508.

40. Murphy RX Jr, Jennings JF, Wukich DK. Major neurovascular complications of endoscopic carpal tunnel release. J Hand Surg Am. 1994; 19(1):114-118.

41. Atroshi I, Larsson GU, Ornstein E, Hofer M, Johnsson R, Ranstam J. Outcomes of endoscopic surgery compared with open surgery for carpal tunnel syndrome among employed patients: Randomised controlled trial. BMJ. 2006;332(7556):1473.

42. Wong KC, Hung LK, Ho PC, Wong JM. Carpal tunnel release. A prospective, randomised study of endoscopic versus limited-open methods. J Bone Joint Surg Br. 2003;85(6):863-868.

43. Tessitore E, Schonauer C, Moraci A. Mini-open carpal tunnel decompression. Neurosurgery. 2004;55(4):1010; author reply 1010.

44. Huang JH, Zager EL. Mini-open carpal tunnel decompression. Neurosurgery. 2004;54(2):397-9; discussion 399-400.

45. Cellocco P, Rossi C, El Boustany S, Di Tanna GL, Costanzo G. Minimally invasive carpal tunnel release. Orthop Clin North Am. 2009;40(4): 441-448, vii.
International Journal of General Medicine

\section{Publish your work in this journal}

The International Journal of General Medicine is an international, peer-reviewed open-access journal that focuses on general and internal medicine, pathogenesis, epidemiology, diagnosis, monitoring and treatment protocols. The journal is characterized by the rapid reporting of reviews, original research and clinical studies across all disease areas.

\section{Dovepress}

A key focus is the elucidation of disease processes and management protocols resulting in improved outcomes for the patient. The manuscript management system is completely online and includes a very quick and fair peer-review system. Visit http://www.dovepress.com/ testimonials.php to read real quotes from published authors. 